\title{
0 ESTÁGIO CURRICULAR SUPERVISIONADO NA EDUCAÇÃO INFANTIL PARA A FORMAÇÃO INICIAL DO PROFESSOR
}

\author{
Susana Soares Tozetto (UEPG)* \\ https://orcid.org/0000-0002-1696-677X \\ Melissa Rodrigues da Silva (UEPG)**
}

\section{RESUMO}

O pedagogo é o sujeito que estuda a complexidade da educação e se torna o mediador dos processos que a envolvem, possibilitando o exercício da docência. 0 curso de Pedagogia concede ao licenciado atuar na Educação Infantil e nos anos iniciais do Ensino Fundamental. Nesse contexto, o recorte que se faz na apresentação da presente pesquisa é proveniente da preocupação com a disciplina de Estágio Curricular Supervisionado em Docência na Educação Infantil no curso de Pedagogia da Universidade Estadual de Ponta Grossa (UEPG), no Paraná. Nesse sentido, o objetivo da investigação foi analisar o estágio curricular na Educação Infantil, visando compreender o seu papel no curso e contribuir para a formação inicial do pedagogo. Para esta pesquisa, foram analisados os relatórios finais da disciplina de Estágio Curricular Supervisionado em Docência na Educação Infantil, documento realizado pelas acadêmicas do terceiro ano do curso, em 2017. A pesquisa contou com a análise documental de 18 relatórios finais de estágio, e, a partir disso, concluiu-se que a disciplina de estágio tem um papel fundamental na formação inicial do futuro profissional, bem como é um espaço formativo e reflexivo da prática pedagógica.

Palavras-chave: Estágio curricular. Formação inicial. Educação infantil.

\section{ABSTRACT}

\section{SUPERVISED CURRICULAR INTERNSHIP IN EARLY CHILDHOOD EDUCATION FOR INITIAL TEACHER EDUCATION}

The Pedagogue is the subject that studies the complexity of education and becomes the mediator of the processes that surround it, making the exercise of teaching possible. The Pedagogy course allows the educator to work in Early

\footnotetext{
Doutora em Educação pela Universidade Estadual paulista Júlio de Mesquita Filho (Unesp). Docente do Departamento de Educação e do Programa de Pós-Graduação em Educação da Universidade Estadual de Ponta Grossa (UEPG). E-mail: tozettosusana@hotmail.com

** Doutoranda em Educação pela Universidade Estadual de Ponta Grossa (UEPG). Docente do Departamento de Pedagogia da Universidade Estadual de Ponta Grossa (UEPG). E-mail: melissarsp@hotmail.com
} 
Childhood Education and in the early grades of Elementary Education. In this context, the cut that is made in the presentation of this research is based on a concern about the discipline of Supervised Curricular Internship in Teaching in the Pedagogy course of the State University of Ponta Grossa (UEPG), Paraná, Brazil. In this sense, the objective of the investigation was to analyze the curricular internship in Early Childhood Education, in order to understand its role in the course and contribute to the initial education of the pedagogue. For this research, the final reports of the discipline of Supervised Curricular Internship in Teaching in Early Childhood Education were analyzed, a document carried out by the undergraduate students of the third year of the course, in 2017. The research counted on the documentary analysis of 18 final reports of internship, and, from this, we concluded that the internship discipline plays a fundamental role in the initial education of the upcoming professional, as well as it is a formative and reflective space of the pedagogical practice.

Keywords: Curricular Internship. Initial education. Early Childhood education.

\section{RESUMEN}

\section{LA PRÁCTICA CURRICULAR SUPERVISADA EN LA EDUCACIÓN INFANTIL PARA LA FORMACIÓN INICIAL DEL PROFESOR}

El Pedagogo es el sujeto que estudia la complejidad de la educación y se convierte en el mediador de los procesos que la involucran, posibilitando el ejercicio de la docencia. El curso de Pedagogía concede al licenciado actuar en la Educación Infantil y en los Años iniciales de la Enseñanza Fundamental. En este contexto, el recorte que se hace en la presentación de esta investigación es proveniente de la preocupación con la disciplina de Práctica Curricular Supervisada en Docencia en la Educación Infantil en el curso de Pedagogía de la Universidad Estatal de Ponta Grossa (UEPG), en Paraná, Brasil. En este sentido, el objetivo de la investigación fue analizar el Práctica curricular en la Educación Infantil, buscando comprender su papel en el curso y contribuir a la formación inicial del pedagogo. Para esta investigación, fueron analizados los informes finales de la disciplina de Práctica Curricular Supervisada en Docencia en la Educación Infantil, documento realizado por las estudiantes del tercer año del curso, en 2017. La encuesta contó con el análisis documental de 18 informes finales de práctica, a partir de eso, se concluyó que la disciplina de práctica tiene un papel fundamental en la formación inicial del futuro profesional, así como es un espacio formativo y reflexivo de la práctica pedagógica.

Palabras clave: Práctica curricular. Formación inicial. Educación infantil.

\section{Introdução ${ }^{1}$}

Nos últimos anos, a formação docente passou por várias e conturbadas modificações, tendo como principal objetivo a amplificação da formação desses profissionais, garantindo uma

\footnotetext{
1 Este artigo contou com a participação de Dayana Oliveira.
}

melhoria na educação. Com as reformulações no âmbito educacional da formação de docentes, os Cursos Normais foram se extinguindo e os cursos de Licenciatura em Pedagogia foram tomando cada vez mais espaço, sendo esse o campo da formação inicial para o pedagogo. 
Assim, concorda-se com Saviani (1985) em seu discurso sobre a Pedagogia e a formação:

Pedagogia significa também condução à cultura, isto é, processo de formação cultural. E pedagogo é aquele que possibilita o acesso à cultura, organizando o processo de formação cultural.É, pois, aquele que domina as formas, os procedimentos, os métodos através dos quais se chega ao domínio do patrimônio cultural acumulado pela humanidade. E como o homem só se constitui como tal na medida em que se destaca da natureza e ingressa no mundo da cultura, eis como a formação humana, convertendo-se o pedagogo, por sua vez, em formador de homens. Por aí se pode perceber por que a palavra pedagogia traz sempre ressonâncias metodológicas, processuais, isto é, de caminho através do qual se chega a determinado lugar. Aliás, isto já está presente na etimologia da palavra: conduzir (por um caminho) até determinado lugar. (SAVIANI, 1985, p. 27).

Para esse autor, o pedagogo é o sujeito que estuda a complexidade da educação e se torna o mediador dos processos que a envolvem, possibilitando a formação humana e o entendimento político, cultural, econômico e social do contexto ao qual se está inserido. É necessário, portanto, que o sujeito que vai atuar nessa área entenda a complexidade da educação e a tome como norte para a construção da sua identidade profissional; além disso, tenha como principal objetivo, em sua carreira, a emancipação dos sujeitos. A partir dessas afirmações, entende-se o curso de Pedagogia como responsável pela formação de profissionais da educação, sendo esse um licenciado com formação teórica/ prática e ética na área da educação.

O curso de Pedagogia concede ao licenciado atuar na Educação Infantil e nos anos iniciais do Ensino Fundamental. Nesse contexto, o recorte que se faz na apresentação da presente pesquisa é proveniente da preocupação com a disciplina de Estágio Curricular Supervisionado em Docência na Educação Infantil no curso de Pedagogia da Universidade Estadual de Ponta Grossa (UEPG), no Paraná. São salutares, nessa disciplina, as possibilidades que os acadêmicos têm de observar, planejar e vivenciar os saberes que fundamentam a formação inicial do professor, oportunizando o primeiro contato com o seu campo de atuação.

No intento de superar a visão burocrática e técnica do estágio na licenciatura, a disciplina abre um leque de inquietações sobre a carreira docente e o contexto educativo, que, em muitos casos, torna necessários estudos aprofundados para superar desafios relacionados à formação docente e à Educação Infantil. Nesse contexto, propõe-se compreender o papel do Estágio Curricular Supervisionado em Docência na Educação Infantil para a formação inicial do professor pedagogo e analisar os relatórios produzidos pelas acadêmicas no ano de 2017. Esse documento, ao final do ano letivo, é tido como parte do processo avaliativo da disciplina de Estágio e também um documento que possibilita reconhecer o processo vivenciado na formação inicial do professor.

Concernente à análise dos documentos, a organização e a efetivação dos estágios curriculares supervisionados foram categorizados, alusivos à proposição da importância da aproximação entre os dois campos formativos: o Centro Municipal de Educação Infantil (CMEI), que recebeu os acadêmicos estagiários, e a Universidade, que outorga tal prática.

\section{Estágio Curricular Supervisionado como parceria entre escola e universidade}

O Estágio Curricular Supervisionado proporciona a aproximação entre a universidade e a escola, sendo este um campo de conhecimento que vai além da relação entre teoria e prática. Nesta pesquisa, resguarda-se que o estágio pode superar ações momentâneas de formação do professor, muitas vezes verticalizadas e fragmentadas com a parceria entre o CMEI e a Universidade. Vislumbra-se a aproximação entre os campos formativos, escola e universidade como proposta para unir, juntar, aproximar, relacionar as ações de maneira ho- 
rizontal, como uma via de mão dupla que compreenda a universidade e a escola como campos formativos docentes de maneira igualitária.

Ao reportar aos campos formativos, Pimenta e Lima (2011, p. 111) ponderam que: "Ao transitar da universidade para a escola e desta para a universidade, os estagiários podem tecer uma rede de relações, conhecimentos e aprendizagens, não com o objetivo de copiar, de criticar apenas os modelos, mas no sentido de compreender a realidade para ultrapassá-la."

O estágio curricular é, portanto, um processo formativo que deve ser capaz de ampliar o saber dos acadêmicos. É o momento de lidar com informações sobre a escola, o aluno, a metodologia e a avaliação, nas quais os sujeitos se defrontam com a realidade, com o contexto cultural e social da profissão. Período de construção de dados e saberes sobre a prática educativa. A efetivação do Estágio Supervisionado como componente curricular obrigatório provoca relações com as diversas áreas da ciência e possibilita o crescimento e a consolidação do conhecimento do futuro professor.

A aproximação da escola e/ou CMEI com a Universidade por meio do Estágio Curricular Supervisionado pode viabilizar uma relação planejada e contínua, que possibilita o ensino e a aprendizagem (do professor que recebe o estagiário e do estagiário), mediante confronto com a realidade escolar. Importa reafirmar que o Estágio Curricular Supervisionado provoca uma aproximação entre os professores de ambas as instituições (CMEI e Universidade), dos que já atuam tanto na escola quanto na universidade e, assim, estabelece vínculos, os quais poderão responder aos anseios e às afrontas cotidianas da prática docente. Quiçá a paridade entre os saberes constituídos na universidade, em parceria com a escola, justapostos em um único objetivo: a formação de bons professores.

Da mesma maneira, os professores da escola e da universidade devem ser parceiros e precisam sentir-se partícipes e facilitadores do processo formativo do futuro docente. Propiciam, assim, em suas ações, ensinamentos que podem ser estabelecidos por meio da organização, do planejamento, do acompanhamento, da avaliação e da análise do Estágio Curricular Supervisionado. Possibilitam o diálogo, a discussão e o conhecimento construído de maneira horizontal e contínuo ao aprendizado do futuro professor.

\section{As Diretrizes Curriculares Nacionais para a Formação Inicial e Continuada dos Professores da Educação Básica (DCN de 2015) e o Estágio Curricular na UEPG}

As questões que tencionam o Estágio Curricular Supervisionado nas licenciaturas percorrem as políticas públicas e os documentos que direcionam os cursos de Pedagogia no Brasil. Dessa maneira, é importante compreender como o Conselho Nacional de Educação (CNE) determina a estrutura do estágio:

Estágio curricular supervisionado de ensino, entendido como o tempo de aprendizagem que, através de um período de permanência, alguém se demora em algum lugar ou ofício para aprender a prática do mesmo e depois poder exercer uma profissão ou ofício. Assim o estágio curricular supervisionado supõe uma relação pedagógica entre alguém que já é um profissional reconhecido em um ambiente institucional de trabalho e um aluno estagiário. Por isso é que este momento se chama estágio curricular supervisionado. Este é um momento de formação profissional do formando seja pelo exercício direto in loco, seja pela presença participativa em ambientes próprios de atividades daquela área profissional, sob a responsabilidade de um profissional já habilitado. (BRASIL, 2015, p. 31).

Ainda, ao percorrer a esteira legal e sobre a disposição dos estágios nas licenciaturas, as Diretrizes Curriculares Nacionais para a Formação Inicial e Continuada dos Profissionais da Educação Básica - DCN (BRASIL, 2015), documento mais recente que rege a formação docente no Brasil, que, após uma década de dis- 
cussões, foram aprovadas no CNE, direcionam o repensar sobre a formação dos profissionais do magistério, no que tange à formação inicial (licenciaturas) e a formação continuada. 0 documento pauta-se em uma disposição teórica sólida e interdisciplinar, pela unidade da teoria e da prática, e coloca o trabalho como princípio educativo na constituição do profissional.

Há de considerar-se que a implementação do documento nas universidades e na reorganização das propostas curriculares do curso de Pedagogia impactaram na restruturação dos estágios. As DCN (BRASIL, 2015) determinam o estágio com 400 horas na área de formação e atuação na Educação Básica, contemplando também outras áreas específicas, se for o caso, conforme o projeto de curso da instituição (BRASIL, 2015).

Em relação à determinação anterior que vigorava sob o curso de licenciatura em Pedagogia (BRASIL, 2006), as DCN (BRASIL, 2015) ampliaram a carga horária dos estágios em 100 horas. Essa foi a mudança mais visível em relação à organização da disciplina, ficando a critério da instituição distribuir as horas conforme o currículo do curso. Com o aumento das cargas horárias obrigatórias da disciplina, pode-se considerar que o estágio vem ganhando mais espaço no currículo das licenciaturas e a preocupação com a Educação Básica tomando forma dentro da universidade de maneira institucionalizada.

As modificações anunciadas pelas DCN (BRASIL, 2015) ainda se referem à prática como componente curricular, e que esta deve produzir aprendizagem do futuro professor no âmbito do ensino e que seja produtivo a eles. Dessa maneira, o documento demanda que:

Uma concepção mais ampla de prática implica em vê-la como uma dimensão do conhecimento que tanto está presente na escola de formação, nos momentos em que se trabalha na reflexão sobre a atividade profissional - e que, portanto, o foco da reflexão deve estar no conteúdo das práticas, quanto está presente nas escolas campo de estágio, nos momentos em que se trabalha na atividade profissional - e, que, portanto, o foco da reflexão deve estar na significação e ressignificação do conteúdo das práticas. (BRASIL, 2015, p. 29).

O planejamento e a execução das práticas pedagógicas devem apoiar-se nas reflexões desenvolvidas na escola e na universidade, devem constituir-se em conteúdo para o trabalho do docente e seu entendimento sobre a docência. A ideia a ser superada é a de que, na universidade, tem-se a teoria e, na escola, a prática. A relação teórico-prática deve ser uma constante nas atividades desenvolvidas pelos estagiários, de forma a retomar e relacionar os conteúdos tratados nos fundamentos da educação com as ações realizadas na escola no exercício da docência.

O que fica notório ainda no documento é que, em vários momentos, o texto convoca para a discussão sobre a importância da articulação entre a universidade e a escola, ou seja, entre a Educação Básica e a Educação Superior. As DCN (BRASIL, 2015) indicam que a aproximação entre a universidade e a escola possibilitará aos futuros professores o acesso aos princípios da pesquisa. Assim, a pesquisa passa a ser destaque nas ações pedagógicas no estágio.

A pesquisa no estágio como método de formação de futuros professores, se traduz, de um lado, na mobilização de pesquisas que permitam a ampliação análise dos contextos onde os estágios se realizam; por outro, e em especial, se traduz na possibilidade de os estagiários desenvolverem postura e habilidades de pesquisador a partir das situações de estágio, elaborando projetos que lhes permitam ao mesmo tempo compreender e problematizar as situações que observam. (PIMENTA; LIMA, 2011, p. 46).

Aproximar a pesquisa em educação das duas realidades (universidade e escola) possibilita um novo olhar em relação ao processo formativo docente, no curso de Licenciatura em Pedagogia. A defesa da importância da articulação entre escola e universidade, tanto para a Educação Superior quanto para a Educação Básica, poderá ser vista como uma via de mão dupla. 0 termo "articulação" é entendido, neste estudo, como expresso nas DCN (BRASIL, 2015), como uma ação a ser efetivada, expansiva e que deve 
se estabelecer na universidade e na escola. Em um contexto de crescimento e ampliação, compreende-se a articulação de maneira efetiva e contínua, sem estar apenas disposta nas políticas públicas, sociais e de expansão, mas que supere a fragmentação de ações postas pelas duas instituições. Nessa perspectiva, as DCN (BRASIL, 2015) passam a ser aliadas no processo formativo dos docentes, pois ressaltam a importância de articulação entre escola e universidade, utilizando-se da pesquisa como elemento de integração.

\section{Estágio Curricular Supervisionado na UEPG}

Nesse subtítulo, traz-se a organização do currículo do curso de Licenciatura em Pedagogia da Universidade Estadual de Ponta Grossa (2016), pois é o campo de investigação da presente pesquisa. Para tanto, verificou-se em seu currículo a seguinte estrutura:

[...] o acadêmico deverá perfazer um total mínimo de 3.498 (três mil, quatrocentas e noventa e oito) horas, sendo 1.088 (mil, e oitenta e oito) horas em disciplinas de Formação Básica Geral, 408 (quatrocentas e oito) horas em disciplinas de Prática como Componente Curricular, 1.258 (mil, duzentas e cinquenta e oito) horas em disciplinas de Formação Específica Profissional, 408 (quatrocentas e oito) horas em Estágio Curricular Supervisionado, 136 (cento e trinta e seis horas em disciplinas de Diversificação ou Aprofundamento e 200 (duzentas) horas de Atividades Complementares, distribuídas em, no mínimo, 4 (quatro) anos e, no máximo, 06 (seis) anos letivos em ambos os turnos. (UNIVERSIDADE ESTADUAL DE PONTA GROSSA, 2016, p. 1).

O documento ainda traz, sobre o Estágio Curricular Supervisionado, a seguinte descrição:

O Estágio Curricular Supervisionado, embora incorporado como disciplina de Formação Específica Profissional, será desenvolvido a partir do início da segunda metade do curso, num total e 408 (quatrocentas e oito) horas, de conformidade com o respectivo regulamento aprovado pelo Conselho de Ensino, Pesquisa e Extensão, Resolução CEPE n 17, de 07/03/2006. (UNI-
VERSIDADE ESTADUAL DE PONTA GROSSA, 2016, p. 2).

Como disposto, o acadêmico poderá realizar os estágios a partir da segunda metade do curso $\left(3^{\circ}\right.$ e $4^{\circ}$ anos). A UEPG considera o estágio uma disciplina de formação profissional, que verifica e acompanha o processo educativo e formativo, tanto do acadêmico estagiário como da escola. As 408 (quatrocentos e oito) horas de Estágio Curricular Supervisionado estão distribuídas em 4 disciplinas, quais sejam: Estágio Curricular Supervisionado em Docência na Educação Infantil, 102 horas; Estágio Curricular Supervisionado em Docência nos Anos Iniciais do Ensino Fundamental, 102 horas; Estágio Curricular Supervisionado em Gestão na Educação Básica I, 102 horas; Estágio Curricular Supervisionado em Gestão na Educação Básica II, 102 horas.

0 recorte, nesta pesquisa, dá-se na disciplina de Estágio Curricular Supervisionado em Docência na Educação Infantil, que, em sua ementa, trata dos seguintes aspectos:

Investigação da realidade escolar na Educação Infantil. Análise das concepções educacionais e objetivos vigentes na Educação Infantil, com vistas à problematização das práticas pedagógicas. Elaboração e desenvolvimento de projetos de intervenção no espaço escolar da Educação Infantil. Análise, elaboração e aplicação de recursos e materiais didático-pedagógicos pertinentes ao trabalho docente na Educação Infantil. Análise crítico reflexiva do processo de estágio vivenciado. (UNIVERSIDADE ESTADUAL DE PONTA GROSSA, 2016, p. 7).

A disciplina efetiva-se por meio de 51 (cinquenta e uma) horas em aulas presenciais na universidade e 51 (cinquenta e uma) horas em campo de estágio no CMEI, totalizando 102 (cento e duas) horas. As aulas na universidade caracterizam-se pelas discussões que se concretizam a partir do contexto do que é o estágio como componente curricular em um curso de licenciatura e o comprometimento com a formação do professor, que

Envolve muito mais que uma racionalidade teórico técnica, marcada por aprendizagens 
conceituais e procedimentos metodológicos. Há, no reino da prática pedagógica e da formação de professores, muito mais que domínio teórico, competência técnica e compromisso político. Lá estão histórias de vida, crenças, valores, afetividade, enfim, a subjetividade dos sujeitos implicados. (OSTETTO, 2008, p. 126).

A disciplina de estágio no curso de Licenciatura em Pedagogia da UEPG busca fundamentar, observar, planejar e reconhecer a docência na Educação Infantil que acontece nos CMEI. Tais ações incursionam a didática do professor que já atua na Educação Infantil, também por meio dos referenciais já estudados nos anos anteriores do curso. Volta-se para uma reflexão da prática como socialização do conhecimento, a fim de que os acadêmicos estagiários tenham subsídios teórico-práticos para construir e contextualizar a docência como parte do processo educativo.

Ademais, são abordadas duas ações durante a disciplina de estágio: a de aprender e a de ensinar. Uma das maiores preocupações em relação à docência é a direção da turma, que, depois de observada, é repensada juntamente ao professor da disciplina. No momento do estágio, são trazidas à universidade as questões cotidianas do CMEI, as quais são discutidas pelo professor da disciplina e os acadêmicos estagiários, que se deparam com as problemáticas referentes àquele contexto. É o momento de referência da atuação docente e um importante espaço para articulação entre as duas instituições formadoras. Desse modo, o estágio aproxima o acadêmico da realidade da escola, propiciado pela parceria entre universidade e escola: "Ao transitar da universidade para a escola e desta para a universidade, os estagiários podem tecer uma rede de relações, conhecimentos e aprendizagens, não com o objetivo de copiar, de criticar apenas os modelos, mas no sentido de compreender a realidade para ultrapassá-la." (PIMENTA; LIMA, 2011, p. 111).

A organização da disciplina de Estágio sempre busca aproximar a conjuntura da Educação
Infantil ao contexto da Educação Superior (o curso de licenciatura em Pedagogia). No seminário final, que acontece na disciplina de Estágio, desenvolvem-se atividades com o coletivo dos acadêmicos, sendo possível reavaliar as práticas que aconteceram na escola durante as observações e as direções da classe. É um tempo para refletir, analisar sobre as ações realizadas na escola durante o estágio. Após o seminário, os acadêmicos realizam o relatório final, na sua maioria individualmente.

0 relatório final faz parte da avaliação da disciplina de Estágio Curricular Supervisionado em Docência na Educação Infantil. Nele consta toda a descrição do processo do estágio. Em meio a sua composição, percebe-se a importância do documento como um instrumento significativo de análise, em que constam importantes reflexões acerca da Educação Infantil, do estágio como componente curricular e obrigatório e, principalmente, considerações sobre a formação inicial.

Ao narrar a experiência vivida, o professor [acadêmico estagiário] aprende sobre si mesmo e sobre a sua prática, pois ao organizar o pensamento por escrito, na experiência narrativa, constitui um campo de reflexão: toma distância para aproximar, aproxima para aprofundar, aprofunda e reconstitui o vivido com outras cores, de forma ampliada e integrada. [...]. Assim, não é 'só' escrever - simples recordação, lembranças. A palavra escrita é base para a análise do cotidiano, tecendo a história, pessoal e profissional do educador. Escrever, registrando o vivido, humaniza o educador, na medida em que possibilita o encontro com suas dúvidas, deixando-o frente a frente com seus erros, com seus limites. (OSTETTO, 2008, p. 134, grifo nosso).

0 relatório é um instrumento narrativo, produzido durante a formação inicial, ladeado por um processo de análise e de reflexão acerca da docência. Dessa maneira, é uma forma de discurso em que, “[...] ao escrever o relatório, o aluno-mestre recontextualiza práticas sociais experienciadas nas atividades teóricas e práticas dos estágios supervisionados obrigatórios" (SILVA, 2016, p. 9). 
Para a construção dos relatórios, é necessário também ponderação sobre o desenvolvimento da escrita, visto que constam, nesses documentos, alguns elementos essenciais, tais como: introdução; projeto do estágio; planos de ação; registros, por meio de imagens, das atividades desenvolvidas durante a docência; e considerações finais sobre todo o processo vivido no Estágio Curricular Supervisionado. Além disso, os anexos trazem as fichas avaliativas (Avaliação da professora do CMEI - do projeto e da docência, avaliação da professora da disciplina). A descrição e a análise desse documento foram balizadas pela discussão que converge na teoria e na prática que a disciplina proporciona.

\section{Metodologia e análise dos dados coletados na pesquisa}

0 desenho metodológico desta investigação faz-se a partir da pesquisa documental, pois tem-se os relatórios de estágio ${ }^{2}$ como um documento produzido durante o processo formativo das acadêmicas estagiárias do curso de Licenciatura em Pedagogia da UEPG. A pesquisa documental são a coleta de dados e a análise de documentos, as quais ainda não receberam processo analítico. Nesse tipo de pesquisa, pode-se utilizar de diversos documentos escritos ou não, a exemplo dos relatórios, como fonte primária: "A característica da pesquisa documental é que a fonte de coleta de dados está restrita a documentos, escritos ou não, constituindo o que se denomina de fontes primárias. Estas podem ser feitas no momento em que o fato ou fenômeno ocorre, ou depois." (MARCONI; LAKATOS, 2003, p. 174).

Assim sendo, de um total de 91 acadêmicos matriculados na disciplina de Estágio

2 Os relatórios utilizados nesta pesquisa foram elaborados a partir do Estágio Curricular Supervisionado em Docência na Educação Infantil, realizado no ano de 2017 pelas acadêmicas do 3 o ano do curso de Licenciatura em Pedagogia da UEPG. Para reunir os documentos, encaminhou-se e-mails para três turmas de Pedagogia, que no ano de 2018 cursavam o $4^{\circ}$ ano do curso, solicitando autorização para análise do documento (OLIVEIRA, 2018).
Curricular Supervisionado em Docência na Educação Infantil, em 2017, foi possível coletar 18 relatórios (lidos na íntegra), dos quais: 15 documentos produzidos individualmente e 3 documentos em duplas, perfazendo o total de 21 acadêmicas participantes da pesquisa.

Ao realizar a leitura dos relatórios, foi perceptível que as acadêmicas ressaltaram as inquietações levantadas no período das observações e também da direção de turma (docência). As narrativas demonstram que buscaram soluções para as dúvidas e os anseios vivenciados nos CMEI; desse modo, elas puderam compreender que o Estágio Curricular $\mathrm{Su}$ pervisionado é movido pelo olhar investigativo e desvelado para a pesquisa.

Ao analisar os relatórios, observou-se as seguintes categorias: planejamento; organização dos espaços e dos tempos; prática pedagógica; cuidar e educar; e a afetividade. A eleição das categorias justifica-se pelo destaque com que cada expressão se repetiu nos relatórios.

A amostragem dos dados será apresentada em porcentagem, deixando visível de que maneira cada categoria foi se constituindo nos relatórios. Pondera-se que o planejamento foi a categoria mais evidente, atingindo $46 \%$ dos relatos; a organização dos tempos e dos espaços foi uma expressão muito presente nos relatórios e mostrou-se em $21 \%$ dos documentos; e as demais categorias, afetividade (11\%), cuidar e educar $(11 \%)$ e prática pedagógica (11\%), estiveram presentes de maneira igualitária nos relatos.

É notório que algumas categorias sobressaem às outras, por distintos fatores, pois, durante o ano de 2017, foram quatro professoras diferentes as responsáveis pela disciplina. Dessa maneira, mesmo que a ementa seja a mesma para todas as professoras, a organização do programa da disciplina altera-se por diferentes motivos, dentre eles o enfoque e a ênfase dados a cada item que compõe a ementa: a criança, a infância, a Educação Infantil, a observação, o planejamento, a formação docente, entre outros. 


\section{Categorias de análise}

Inicia-se a análise pela categoria que mais se evidenciou, o planejamento, que esteve presente em $46 \%$ dos relatórios. Tal expressão é recorrente no momento da narrativa em que as acadêmicas estagiárias retrataram os objetivos do projeto e os planos de aula. Aparecem também: atividades desenvolvidas nas docências e reflexões sobre planejamento flexível. As acadêmicas destacaram a importância da intencionalidade e do ato de planejar para a Educação Infantil, tendo em vista que esse é o principal instrumento da prática docente, pois não há como desenvolver a aula sem antes planejar as ações.

Nota-se, nos relatórios, que houve discussão e reflexão acerca do processo de planejar, durante a sua execução e nas considerações após a docência (direção de turma). Vale destacar alguns trechos das descrições das acadêmicas estagiárias:

Foi um processo difícil, pois nunca havíamos planejado antes. E também em questão às atividades para a faixa etária, mesmo com estudos na sala de aula da universidade sobre o planejamento, não tínhamos o conhecimento da prática, o que se tornou ainda mais complicado. (ACADÊMICA 6).

Foi um momento de extrema importância e de grande aprendizado na formação, pois o ato de planejar sempre estará em constante construção. (ACADÊMICA 12).

As acadêmicas relataram os temas geradores de seus planejamentos, sobretudo os objetivos a serem alcançados e as descrições das atividades elaboradas nas docências. Ainda descreveram a importância das temáticas para o desenvolvimento e a aprendizagem das crianças, traçando, assim, objetivos adequados à faixa etária, sendo possível de serem alcançados. Também se reportaram ao desenrolar das atividades, nas quais buscaram elaborar e desenvolver propostas que dessem conta das interações e das brincadeiras para a Educação Infantil. As acadêmicas concluíram que é uma atividade difícil, pois envolve reflexão acerca do ato de ensinar.

A segunda categoria, nesta análise, é a organização dos espaços e dos tempos, que aparece em 21\% dos relatórios. No bojo da categoria, reuniram-se alguns elementos, tais como: a preocupação da organização do tempo e do espaço para o desenvolvimento e a aprendizagem das crianças; a descrição dos espaços (sala, pátio, refeitório etc.); a visibilidade da criança no tempo e no espaço do CMEI como protagonista; e os espaços brincantes criados pela instituição.

A preocupação das acadêmicas estagiárias quanto à organização do tempo e do espaço na Educação Infantil é decorrente do que se traduz nos documentos que balizam essa etapa de ensino, bem como a Educação Básica. Considera-se importante o que anunciam as Diretrizes Curriculares da Educação Básica (DCEB):

As instituições de Educação Infantil devem tanto oferecer espaço limpo, seguro e voltado para garantir a saúde infantil quanto se organizar como ambientes acolhedores, desafiadores e inclusivos, plenos de interações, explorações e descobertas partilhadas com outras crianças e com o professor. Elas ainda devem criar contextos que articulem diferentes linguagens e que permitam a participação, expressão, criação, manifestação e consideração de seus interesses. (BRASIL, 2013, p. 91).

Visto que a criança se torna a protagonista do espaço que ocupa, sendo ela capaz de modificá-lo conforme as suas necessidades, concerne ao professor pensar e criar ambientes que favoreçam o seu desenvolvimento integral.

Projetar o espaço de uma creche ou pré-escola [...] é um evento altamente criativo, não apenas em termos de pedagogia e arquitetura, mas em termos sociais, culturais e políticos. A instituição escolar, na verdade, pode desempenhar um papel muito especial no desenvolvimento cultural e na experimentação sociopolítica, na medida em que esse momento (projeção) e esse lugar (a escola) podem ser experienciados não como tempo e espaço para reproduzir e transmitir conhecimentos já estabelecidos, mas como um lugar para a verdadeira criatividade. (RINALDI, 2013, p. 122). 
Na tessitura desta análise, fica notório nos relatos que os espaços são instrumentos que devem proporcionar o ensino e a aprendizagem das crianças, sendo uma ferramenta a ser inserida de maneira decisiva no planejamento. As acadêmicas ressaltam que é essencial planejar os espaços e os tempos adequados para cada tipo de atividade que desejam realizar com as crianças.

Nas narrativas, as estudantes também mencionaram a criação de espaços lúdicos, denominados "cantinhos", sendo espaços de leitura, de brincadeiras, de fantasias etc. Da abordagem trazida nos relatórios, compreende-se que os espaços podem propiciar momentos de lazer e de diversão, mas é necessário que também haja uma intencionalidade de aprendizagem. Dessa forma, percebe-se nos relatórios de estágio que é necessário pensar em espaços e tempos que valorizem e respeitem as diferenças culturais, sociais e de identidades das crianças inseridas na instituição, além de satisfazer a imaginação, a criatividade e as descobertas, de modo a proporcionar momentos de participação e de relação entre os indivíduos.

Entretanto, as acadêmicas retrataram nos relatórios que, ao tomarem como referência o tempo e o espaço, foi possível constatar que a organização foi pensada para facilitar a vida do adulto, criando ações que favorecessem o trabalho do professor, deixando de lado as necessidades inerentes ao processo de desenvolvimento da criança. Dessa maneira, as estagiárias perceberam que as crianças não receberam a devida atenção nos espaços destinados a elas; assim, elas não se tornam protagonistas do meio em que estão inseridas e não se identificam com o ambiente. As acadêmicas perceberam a necessidade de criar ambientes com os quais as crianças se identifiquem, participem e recriem espaços que possam se desenvolver. Ainda nessa categoria, as acadêmicas descreveram um minucioso detalhamento dos ambientes do CMEI, como: a decoração das salas de aula; a quantidade de salas de aula, banheiros, refeitórios, salas das diretoras, pedagogas e professores, além dos demais mobiliários.

A prática pedagógica apareceu em 11\% dos relatórios. Nesta categoria, as acadêmicas relataram a importância de reavaliar as práticas, reconhecendo que o CMEI é o mediador dessa ação. "A prática pedagógica é aquela que se movimenta reflexivamente frente a dialética que marca a relação teórico-prática no processo educativo buscando direcioná-la à uma dada intencionalidade" (NADAL, 2016, p. 17). Ela é um conjunto de elementos e ações para se chegar a uma finalidade; para tanto, é necessário que haja uma intencionalidade de ações para que se obtenha um resultado positivo frente ao desenvolvimento e à aprendizagem das crianças. Em vista disso,

[...] a prática pedagógica e situada num espaçotempo-organização educativo, possui a característica de ser coletiva. Ela não se dá isolada; é inter-humana e ocorre na coletividade, pois além da dimensão social que lhe é inerente (humanização como apropriação da cultura historicamente constituída pela civilização), é trabalho - atuação do homem no mundo para alcançar valores e objetivos a que se propõe e este, pelas necessidades que se lhe interpõem, se faz em divisão com outros homens, mediada pela divisão social do trabalho. 0 coletivo é uma condição das organizações pois na escola, de modo especial, há uma diversidade de agentes educadores. (NADAL, 2016, p. 24, grifo do autor).

Nos relatórios, ficou perceptível que as práticas pedagógicas da Educação Infantil devem ser organizadas em torno da criança e de seu desenvolvimento integral. Logo, no estágio, percebe-se que há uma fragilidade na reprodução das práticas, pois, em muitos casos, as práticas desenvolvidas não são pensadas em prol da aprendizagem das crianças, mas, sim, na facilidade do trabalho do professor.

Contudo, nos relatos em torno dessa categoria, as acadêmicas julgam que o estágio se dá em um processo coletivo e, acima de tudo, em um momento de reavaliar as práticas até então concebidas. Desse modo, o estágio como campo formativo possibilita que os estagiários 
iniciem a sua construção de prática com o coletivo, com os indivíduos envolvidos no CMEI. Mediante leitura dos relatórios, conclui-se que as acadêmicas constataram que é também por intermédio do estágio que elas podem discutir e, consequentemente, reavaliar as ações dos professores que já atuam no CMEI.

Também é imprescindível que o cuidar e educar esteja na prática pedagógica da Educação Infantil. Essa categoria foi mencionada em $11 \%$ dos documentos analisados, sendo destacada como uma relação de aproximação, de atenção e de afeto entre as crianças, necessitando do professor como mediador das ações. O cuidar e o educar são processos complementares e indissociáveis e princípios importantes a serem considerados na elaboração dos planos de aula.

O cuidar e o educar estão presentes no cotidiano da Educação Infantil. As crianças pequenas necessitam de atenção todo tempo, e em todas as atividades que realizam. Dessa forma, percebe-se, ao analisar os relatórios, que as atividades inerentes ao processo de cuidar foram evidenciadas, sendo os hábitos de higiene e a alimentação um mediador a mais para auxiliar as crianças. Contudo, cuidar e educar são processos que se complementam e são inseparáveis, como traz o documento das Diretrizes Curriculares Nacionais para a Educação Infantil (BRASIL, 2010, p. 19): "A educação em sua integralidade, entendendo o cuidado como algo indissociável ao processo educativo". É necessário, portanto, que haja uma articulação entre os dois processos, cabendo ao professor criar situações de aprendizagem para haver uma relação afetiva entre ambos.

Nos relatórios, foi o cuidar e o educar um dos fatores a serem pensados na elaboração dos planos de aula, indo além das atividades de higiene do cotidiano das crianças no CMEI. É essencial pensar em atividades que ultrapassam o dia a dia, articulando outros conhecimentos com os cuidados básicos pessoais.

As acadêmicas concordaram com os relatos dos documentos da Educação Infantil quando mencionaram a importância de se estabelecer uma relação confiável entre o professor e a criança, uma relação de intimidade, para que esta se sinta confortável nas situações de cuidados. Para tanto, o professor deve criar laços afetivos com cada criança, de forma a tornar mais fácil o acesso a elas, e estabelecer uma analogia de confiança entre ambos. Assim, o professor poderá identificar as situações que as crianças estão vivenciando e obter diagnóstico de cada uma delas.

Elenca-se, desse modo, uma categoria de análise no que diz respeito à afetividade em torno da Educação Infantil, ficando evidente que essa relação é essencial no processo de desenvolvimento da aprendizagem das crianças. Entretanto, o quesito afetividade foi abordado em apenas $11 \%$ dos relatórios. Foi mencionada a relação entre professor e criança como um fator essencial no desenvolvimento desta. Destaca-se aqui um relato de dificuldade em estabelecer uma relação de afeto entre as crianças por meio de uma estagiária, pois o tempo de permanência na escola foi insuficiente para criar esses laços. A afetividade na Educação Infantil é imprescindível, pois, de acordo com Almeida (2010), nos ambientes infantis, as relações afetivas entre os indivíduos envolvidos é um forte fator que influenciará no crescimento da criança. Por intermédio de boas interações há um melhor desempenho na aprendizagem e no desenvolvimento dos pequenos.

O desenvolvimento infantil dependerá da particularidade de cada criança e, também, das relações com o meio em que ela está inserida. Por conseguinte, as relações que as crianças estabelecem com o meio físico e social influenciará em seu desenvolvimento integral. Para tanto, é necessário que os adultos se atentem com as relações emocionais, propiciando um ambiente prazeroso e de afeto com a criança (ALMEIDA, 2010).

Partindo dos elementos da categoria proposta, nos relatórios analisados, os relatos apresentam que a relação de afetividade que o professor tem com as crianças foi denomi- 
nada como uma boa relação, sendo de suma importância criar um vínculo afetivo com os alunos. As acadêmicas compreendem que a relação que o professor estabelece com a criança influenciará na sua aprendizagem e no seu desenvolvimento.

Os relatórios destacam, ainda, que, durante o percurso do estágio, foi possível criar um vínculo afetivo (para a maioria das acadêmicas) com as crianças, o que se tornou essencial no andamento da docência, obtendo-se, desse modo, um resultado positivo ao final do processo. Contudo, uma das acadêmicas relatou que não conseguiu estabelecer relação afetiva, pois a professora regente da turma passou orientações de não abraçar ou beijar as crianças, para que ela não perdesse a autoridade que mantinha com a turma. A acadêmica ainda descreveu que esse foi um fator que interferiu na qualidade de suas aulas. Em muitos casos, as professoras sentem-se inseguras com a sua autoridade quando estabelecem um vínculo afetivo, com receio de perder o domínio da turma. Tendo em vista essa hesitação, muitas preferem não estabelecer laços afetuosos com as crianças.

Outras situações que se configuram são professoras que acabam tornando-se as protetoras das crianças, estabelecendo relações de extremo zelo, as quais acabam criando um sentimento de ciúmes, não permitindo que outras pessoas se aproximem. Foi descrito e destacado como essencial a quantidade de crianças nas turmas, pois quando havia menor número de crianças, a interação foi mais fácil, tanto entre as crianças como entre elas e a professora, além de ter melhor envolvimento no desenvolvimento, no ensino e na aprendizagem.

Diante da amostra dos dados e da análise apresentada neste artigo, considera-se que as acadêmicas do curso de Licenciatura em Pedagogia da UEPG compreenderam o campo de estágio como um momento de formação. Elas trouxeram situações e experiências, vivenciadas a partir da inserção no CMEI e na sala de aula, que contribuem para a formação inicial.

\section{Considerações finais}

No decorrer desta pesquisa foi possível estudar e apresentar o Curso de Licenciatura em Pedagogia na UEPG, salientando a disciplina de Estágio Curricular Supervisionado em Docência na Educação Infantil. Os relatórios finais das acadêmicas do terceiro ano do curso, do ano de 2017, que fizeram parte da avaliação da disciplina, foram analisados. 0 intuito foi coletar informações e considerações pertinentes ao estágio e à formação inicial, sendo esse percurso necessário para compreender o papel do Estágio Curricular Supervisionado em Docência na Educação Infantil para a formação inicial. Dessa maneira, pode-se concluir que a análise realizada teve um resultado satisfatório, pois, considerando os relatos das acadêmicas, percebe-se que o estágio vai além do cumprimento da carga horária, passando a ser um momento de avançar no que se refere à criticidade e à avaliação da docência.

Sobre a organização do curso de Licenciatura em Pedagogia e do estágio na UEPG, concluise que o curso de Pedagogia, especificamente a disciplina de Estágio Curricular Supervisionado em Docência na Educação Infantil, vem ganhando espaço e importância ao longo dos anos, o que acarreta uma significativa melhoria na qualidade educacional. Entretanto, há algumas fragilidades que ainda precisam ser solucionadas, já que o curso não oferece uma disciplina que trate especificamente da organização metodológica da Educação Infantil. Dessa maneira, as acadêmicas do terceiro ano têm muitas dificuldades na compreensão de como se organizam a rotina, os tempos, os espaços, o currículo, os projetos, a avaliação, entre outros aspectos que norteiam o cotidiano do CMEI, o que implica diretamente nas aulas da disciplina de Estágio. Contudo, a disciplina de Estágio Curricular Supervisionado, ao longo do processo formativo docente, passa a ganhar significado na formação inicial, sendo um momento para os estagiários terem contato com a realidade na escola. 
Por meio da análise dos relatórios das acadêmicas, percebeu-se que o Estágio Curricular Supervisionado em Docência na Educação Infantil traz significativas contribuições para a formação inicial das estudantes, tendo um peso forte na construção de sua identidade profissional, pois é o lugar de reflexão em torno das práticas e do contexto da Educação Infantil. É a partir da inserção no campo de estágio que se tem contato com a realidade profissional, o que, para muitas acadêmicas, é a primeira convivência com as crianças. Com a leitura dos relatórios, foi possível observar a importância do estágio para a compreensão das acadêmicas acerca da realidade da escola, sendo imprescindível na formação inicial dos professores.

O estágio é um campo de formação, rico em aprendizagens e reflexões, tornando-se um instrumento valioso na formação inicial. Isso estimula ainda mais os momentos de reflexão sobre a docência ao longo do processo de estágio, possibilitando novos estudos e olhares sobre as práticas pedagógicas.

\section{REFERÊNCIAS}

ALMEIDA, Ana Rita Silva. O lugar da emoção na sala de aula. In: ALMEIDA, Ana Rita Silva. A emoção na sala de aula. 8. ed. Campinas, SP: Papirus, 2010. p. 89-104.

BRASIL. Resolução CNE/CP no 1, de 15 de maio de 2006. Institui Diretrizes Curriculares Nacionais para o Curso de Graduação em Pedagogia, licenciatura. Diário Oficial [da] República Federativa do Brasil, seção 1: Poder Executivo, Brasília, DF, n. 92, p. 11-12, 16 maio 2006.

BRASIL. Ministério da Educação. Diretrizes Curriculares Nacionais da Educação Básica. Brasília, DF, 2013.

BRASIL. Ministério da Educação. Diretrizes Curriculares Nacionais para a Educação Infantil. Brasília, DF, 2010.
BRASIL. Ministério da Educação. Diretrizes Curriculares Nacionais para a Formação Inicial e Continuada dos Profissionais do Magistério da Educação Básica. Brasília, DF, 2015.

MARCONI, Marina de. Andrade; LAKATOS, Eva Maria. Técnicas de pesquisa. In: MARCONI, Marina de. Andrade; LAKATOS, Eva Maria. Fundamentos de metodologia científica. 5. ed. São Paulo: Atlas, 2003. p. 174-214.

NADAL, Beatriz Gomes. Prática pedagógica: a natureza do conceito e formas de aproximação. In: SILVA, Maria Cristina Borges da (org.). Práticas pedagógicas e elementos articuladores. Curitiba: Universidade Tuiuti do Paraná, 2016. p. 15-37.

OLIVEIRA, Dayana. Docência na educação infantil: uma análise a partir dos relatórios de Estágio Curricular Supervisionado do curso de Pedagogia da UEPG. 2018. 50 f. Trabalho de conclusão de curso (Licenciatura em Pedagogia) - Universidade Estadual de Ponta Grossa, Ponta Grossa, PR, 2018.

OSTETTO, Luciana Esmeralda (org.). Educação infantil: saberes e fazeres da formação de professores. Campinas, SP: Papirus, 2008.

PIMENTA, Selma Garrido; LIMA, Maria Socorro Lucena. Estágio e docência. 6. ed. São Paulo: Cortez, 2011.

RINALDI, Carla. 0 ambiente da infância. In: CEPPI, Giulio; ZINI, Michele (org.). Crianças, espaços, relações: como projetar ambientes para educação infantil. Porto Alegre: Penso, 2013. p. 122-126.

SAVIANI, Demerval. Sentido da Pedagogia e papel do pedagogo. Revista Ande, São Paulo, n. 9, p. 2728, 1985.

SILVA, Maria Cristina Borges da. et al. Prática Pedagógica: a natureza do conceito e formas de aproximação. In: SILVA, Maria Cristina Borges da (org.). Práticas pedagógicas e elementos articuladores. Curitiba: Universidade Tuiuti do Paraná, 2016. p. 172-199.

UNIVERSIDADE ESTADUAL DE PONTA GROSSA (UEPG). Catálogo geral 2016. Ponta Grossa, PR, 2016. Disponível em: http://www.uepg.br/ catalogo/cursos/2016/pedagogo.pdf. Acesso em: 20 jul. 2018. 